\title{
INTERNALISASI NILAI PENDIDIKAN KARAKTER PADA MASYARAKAT ADAT KAMPUNG PULO DALAM PEMBELAJARAN NILAI-NILAI KEMENTERIAN ENERGI DAN SUMBER DAYA MINERAL
}

\author{
M. Tajudin Zuhri ${ }^{1)}$ Ani Maliani ${ }^{2)}$ \\ ${ }^{1)}$ Universitas Islam Negeri Sunan Gunung Djati Bandung \\ ${ }^{2}$ Pusat Pengembangan Sumber Daya Manusia Aparatur KESDM
}

\begin{abstract}
ABSTRAK
Kebudayaan yang terdapat pada beberapa masyarakat adat di Indonesia banyak mengandung nilai luhur budaya bangsa yang masih kuat, namun kebudayaan yang berbentuk nilai kearifan lokal sering kali diabaikan, karena dianggap tidak sesuai dengan perkembangan zaman. Padahal dari kearifan lokal tersebut bisa dijadikan model dalam pengembangan budaya bangsa Indonesia khususnya pembelajaran nilai-nilai organisasi.

Dalam konteks inilah penelitian dilaksanakan untuk melihat bagaimana masyarakat adat sebagai kelompok minoritas menginternalisasi nilai-nilai budayanya menjadi nilai yang kohesif dan merefleksi dalam karakter yang kuat. Masyarakat adat yang berada di Kampung Pulo Desa Cangkuang Kecamatan Leles Kabupaten Garut Provinsi Jawa Barat, merupakan kelompok masyarakat adat yang tetap menginternalisasi dan melestarikan nilai-nilai tradisi menjadi karakter warga masyarakatnya.

Jenis penelitian ini menggunakan pendekatan kualitatif dengan jenis etnografi yaitu penelitian yang dilakukan di lingkungan masyarakat adat tertentu. Adapun tujuan yang ingin dicapai dalam penelitian ini adalah mendeskripsikan secara singkat internalisasi nilai budaya dari masyarakat kampung adat yang bisa dipromosikan sebagai basis pembentuk karakter Bangsa Indonesia dan internalisasi nilai-nilai organisasi.

Berdasarkan analisis dari berbagai fakta yang ada kaitannya dengan kampung Pulo, maka dapat disimpulkan bahwa masyarakat kampung Pulo merupakan kampung adat yang sampai saat ini masih eksis memegang teguh tradisi yang telah diwariskan leluhurnya. Hal ini disebabkan karena mereka masih memiliki aturan adat yang dipegang teguh.
\end{abstract}

Kata Kunci: internalisai nilai, Pendidikan Karakter, Kampung Pulo.

The culture that is found in some indigenous peoples in Indonesia contains a lot of national cultural values which are still strong. But culture in the form of local wisdom values is often ignored, because it is not considered in accordance with the times. In fact, local wisdom can be used as a model in the development of Indonesian culture and organization values learning.

In this context that research is carried out to see how indigenous peoples as minority groups internalize their cultural values into cohesive values and reflect in strong character. Indigenous peoples who are in Kampung Pulo, Desa Cangkuang, Kecamatan Leles, Kabupaten Garut, West Java Province, are indigenous groups who continue to internalize and preserve traditional values into the character of their citizens.

This type of research uses a qualitative approach with ethnographic types, namely research conducted in a particular indigenous community environment. As for the objectives to be achieved in this study is to briefly describe the internalization of cultural values of indigenous villages that can be promoted as the basis for forming the character of the Indonesian Nation and organization values internalization

Based on an analysis of various facts that are related to the kampong pulo, then it can be concluded that the community of kampong pulo is a traditional village that still exists to uphold the traditions that have been inherited from their ancestors. This is because they still have customary rules that are adhered.

Keywords: Value internalization, Character Education, Kampung Pulo 


\section{PENDAHULUAN}

Menghubungkan nilai-nilai budaya asli milik masyarakat Indonesia dalam kajian Pendidikan Karakter menjadi kajian yang menarik. Pendidikan Karakter pada umumnya memiliki fungsi pokok dalam dua arah, ke dalam dan ke luar. $\mathrm{Ke}$ dalam yaitu mencetak warga negara yang baik, dan ke luar, mengembangkan warga dunia yang baik.

Pendidikan karakter dapat dimaknai sebagai suatu proses pendidikan secara holistis yang menghubungkan dimensi moral dengan ranah sosial dalam kehidupan pembelajar sebagai fondasi bagi terbentuknya generasi yang berkualitas yang mampu hidup mandiri dan memiliki prinsip suatu kebenaran yang dapat dipertanggung jawabkan (Raharjo, 2010)

Untuk memperkuat nilai-nilai karakater organisasi dan cinta tanah air, maka pada titik ini, pengenalan dan pemahaman tentang budaya lokal menemukan urgensinya. Ia bukan semata untuk mengenalkan nilai budaya lokal, tetapi juga untuk menjaga agar masyarakat bangsa kita tidak tercerabut dari akar budayanya sendiri.

Penelitian ini membahas tentang nilai budaya yang tumbuh, berkembang dan dipertahankan oleh masyarakat adat Kampung Pulo yang secara administratif berada di Desa Cangkuang Kecamatan leles Kabupaten Garut, Jawa Barat. Nilai budaya itu tetap dipertahankan bukan semata karena adat, tetapi mengandung nilai-nilai kebaikan bagi masyarakat pendukungnya, hal ini menjadi pembelajaran nilai-nilai organisasi dapat terinternalisasi dan tumbuh organik dalam budaya organisasi.

\section{KAJIAN TEORI}

Definisi tentang nilai dikemukakan oleh Richard Merril, menurutnya nilai adalah patokan atau standar pola-pola pilihan yang dapat membimbing seseorang atau kelompok ke arah satisfaction, fulfillment, and meaning.

Nilai juga bisa diketahui dengan cara memperbandingkannya dengan fakta. Fakta adalah sesuatu yang ada atau berlangsung begitu saja. Sementara nilai adalah sesuatu yang berlaku, sesuatu yang memikat atau menghimbau kita. Nilai berperanan dalam suasana apresiasi atau penilaian dan akibatnya sering akan dinilai secara berbeda oleh orang banyak. Nilai selalu berkaitan dengan penilaian seseorang, sementara fakta menyangkut ciri-ciri obyektif saja. (Bertens, 2007).

Internalisasi nilai adalah penghayatan terhadap suatu ajaran, ajaran, doktrin, atau nilai sehingga menumbuhkan keyakinan dan kesadaran akan kebenaran doktrin yang diwujudkan dalam sikap dan perilaku. Internalisasi nilai dapat juga dimaknai sebagai upaya yang dilakukan untuk memasukan nilai-nilai ke dalam jiwa sehingga menjadi miliknya. (Ihsan, 1997) Dalam menginternalisasikan nilai, Simon, Howe, dan Kirschenbaum dalam Wahab menawarkan 4 (empat) pendekatan yang dapat digunakan, yaitu pendekatan penanaman moral, pendekatan transmisi nilai bebas, pendekatan teladan, dan pendekatan klarifikasi nilai. (Aziz, 2007).

Kaitannya dengan pengaruh nilai terhadap budaya organisasi (Moeheriono, 2012) mengungkapkan yang menumbuhkan komitmen anggota organisasi dalam pencapaian tujuan organisasi.

Tahap transinternalisasi dimulai dari tahap yang paling sederhana sampai yang kompleks meliputi menerima (receiving) yaitu obyek bersedia menerima nilai-nilai baru yang dikembangkan dalam sikap afektifnya, menanggapi (responding) yaitu kesediaan untuk merespon nilai-nilai yang ia terima dan memiuliki kepuasaan untuk merespon nilai, memberi nilai (valuing) yaitu mampu memberikan makna baru terhadap nilai-nilai yang muncul dengan kriteria nilai yang diyakini kebenarannya, mengorganisasi nilai (organization of value) yaitu pengaturan berlakunya sistem nilai yang diyakini oleh subyek sebagai kebenaran dalam kepribadiannya sehingga ia memiliki satu sistem nilai yang berbeda dengan yang lainnya, karakteristik nilai (Characterization by a value or value complex) yaitu membiasakan nilai-nilai yang diyakini, dan yang telah diorganisir dalam laku pribadinya sehingga nilai tersebut menjadi watak (karakter) yang tidak dapat dipisahkan lagi dari kehidupannya. (Muhaimin, 2004)

Dalam konteks psikologi, internalisasi tidak lebih dari sebuah cara membangun dan mengembangkan dimensi-dimensi kejiwaan. Dengan bahasa lain, psikologi mendorong kesadaran kebatinan terhadap nilai-nilai tertentu agar diimplementasikan dalam kehidupan sehari-hari.

\section{METODE PENELITIAN}

Penelitian ini dilakukan di kampung pulo Provinsi Jawa Barat. Alasan pemilihan desa ini, karena masih kental dalam menjalankan kearifan lokal kampong pulo. Pendekatan penelitian ini menggunakan penelitian kualitatif karena permasalahan penelitian yang dikaji bersifat kompleks, holistik, dinamis dan penuh makna. Peneliti mencoba untuk memahami makna-makna sosial yang muncul dilingkungan obyek penilitian secara mendalam, berusaha menemukan pola, hipotesis dengan menggunakan teori untuk 
mengkaji obyek penelitian. (Sugiyono, 2011) Adapun jenis pendekatan penelitian adalah etnografis. Peneliti mencari berbagai pola (mendeskripsikan sebagai ritual, perilaku sosial adat, atau kebiasaan) dari aktivitas mental kelompok tersebut yang direfleksikan melalui tindakan mereka yang diamati peneliti. Pengumpulan data dilakukan dengan mendatangi tempat penelitian, observasi kehidupan subjek penelitian, wawancara dan dokumentasi.

Dalam pembelajaran nilai-nilai Kementerian ESDM, menggali metoda pembelajaran yang tepat dalam menggali nilai-nilai Kampung Pulo yang dapat dijadikan contoh dalam penerapan nilai dan budaya.

\section{HASIL PENELITIAN DAN PEMBAHASAN Sosiografi Kampung Pulo}

Kampung Pulo merupakan sebuah perkampungan adat yang dihuni oleh sekelompok masyarakat yang masih kuat dalam memegang nilai-nilai budaya peninggalan leluhur (karuhun) mereka. Hal ini terlihat jelas perbedaannya jika dibandingkan dengan masyarakat lain di Iuar Kampung Pulo. Masyarakat adat ini hidup pada suatu tatanan yang dikondisikan dalam suasana kesederhanaan, keselarasan dengan alam, dan tuntunan nilai-nilai budaya yang secara turun temurun diwariskan.

Secara geografis, lokasi Kampung Pulo yang bersebelahan dengan Candi Cangkuang berada pada posisi strategis. Kampung Pulo ini masuk dalam kawasan cagar budaya yang dijadikan sebagai obyek wisata. Letak Kampung Pulo yang berada di tengah Situ Cangkuang memberikan manfaat besar bagi anggota masyarakatnya, sebab air situ tersebut dapat digunakan untuk keperluan mandi, mencuci, penanaman ikan, serta usaha transportasi bagi pemilik rakit dan sebagai ajang rekreasi (Munawar, 2003)

Secara administratif, lokasi Kampung Pulo yang berada di wilayah R T 03 RW 15 Desa Cangkuang tersebut memungkinkan terjadinya mobilitas yang tinggi. Hubungan antar warga masyarakat adat Kampung Pulo dengan masyarakat luar Kampung Pulo dapat berjalan dengan baik, sebab telah tersedia sarana transportasi dan perhubungan yang memadai. Masyarakat adat Kampung Pulo dapat menjangkau daerah di sekelilingnya, seperti Desa Neglasari dan Desa Talagasari di Kecamatan Kadungora, Desa Karanganyar, Desa Tambaksari Kecamatan Leuwigoong, Desa Margaluyu, Desa Sukarame dan Desa Leles di Kecamatan Leles. Letaknya yang strategis tersebut memungkinkan proses akulturasi budaya berlangsung antara budaya di dalam dengan budaya di luar Kampung Pulo.

Berkaitan dengan keberadaan penduduk, masyarakat adat Kampung Pulo merupakan keturunan dari Embah Dalem Arif Muhammad. Dalam enam keluarga inti (berjumlah 21 orang, 10 orang laki-laki dan 11 orang perempuan). Di setiap rumah terdapat 3-4 orang anggota keluarga. Mereka yang tinggal di Kampung Pulo adalah para orang tua dan anak-anak mereka yang masih menempuh pendidikan.

Jumlah keluarga yang ideal tersebut karena adanya ketentuan yang mengharuskan setiap keluarga hanya terdiri dari satu keluarga inti. Ketentuan ini mengharuskan setiap anggota keluarga yang menikah dan memiliki keluarga inti yang baru untuk segera meninggalkan Kampung Pulo. Hal ini memungkinkan tetapnya jumlah anggota masyarakat adat Kampung Pulo.

Disamping itu, dalam ketentuan itu tersirat keharusan bagi setiap anak laki-laki yang akan menikah untuk mempersiapkan segala perbekalan, termasuk menyediakan tempat tinggal bagi keluarga baru mereka. Mereka tidak akan lagi terus bergantung untuk tinggal bersama di rumah orang tua mereka. Di sini terkandung nilai budaya yang berorientasi ke masa depan, dimana masa depan keluarga baru mereka benar-benar dipersiapkan dengan sebaik-baiknya.

Masyarakat adat Kampung Pulo memiliki pekerjaan yang secara rutin mereka lakukan. Tak heran, karena pekerjaannya itu, kondisi keseharian lingkungan masyarakat adat Kampung Pulo pada saat hari-hari kerja adalah sepi, hanya beberapa orang tua yang tinggal di sana. Keseharian mereka, mereka habiskan untuk bekerja agar mendapatkan penghasilan guna memenuhi kebutuhan hidup mereka, baru pada saat sore hari mereka berkumpul. Dalam kegiatan keseharian ini, terungkap pula nilai budaya mereka yang memandang kerja untuk nafkah hidup dan untuk menambah karya.

Ditinjau dari segi etnik, masyarakat adat Kampung Pulo tennasuk suku bangsa Sunda. (Harsojo 1993:30) mengemukakan bahwa suku bangsa Sunda adalah orang-orang yang secara turun temurun menggunakan bahasa ibu bahasa Sunda serta dialeknya dalam kehidupan seharihari, dan berasal serta bertempat tinggal di daerah Jawa Barat, daerah yang juga disebut Tanah Pasundan atau Tatar Sunda. Dalam hal penarikan garis keturunan, setiap anggota keluarga suku bangsa Sunda akan mengenal semua anggota kerabatnya, baik garis keturunan dari pihak lakilaki maupun garis keturunan pihak perempuan (kekerabatan bilateral atau parental). Dengan 
demikian, masyarakat adat Kampung Pulo menarik garis keturunan melalui garis ibu dan bapak. Dalam sistem kekerabatan bilateral, baik pihak bapak maupun pihak ibu dinilai dan diberi derajat yang sama bagi si anak (Ranidar Darwis, 1998:23).

Berkaitan dengan sistem pewarisan, khusus di dalam lingkungan Kampung Pulo, yang berhak memperoleh harta warisan rumah adat adalah anak perempuan. Walaupun demikian, setiap harta kekayaan (yang dapat diwariskan) lainnya diwariskan tidak hanya kepada anak perempuan tetapi kepada semua pihak yang dalam ketentuan Islam atau berdasarkan sistem pewarisan masyarakat Sunda berhak menerima warisan.

Dari sisi kepercayaan, di dalam masyarakat adat Kampung Pulo terdapat perpaduan (sinkretisme) antara Islam dan Hindu. Hal itu tergambar dari kegiatan keagamaan dan upacaraupacara khusus (adat) seperti pada setiap tanggal 14 Mulud (Rabiul Awwal), dan upacara-upacara yang berkaitan dengan lingkaran hidup (Loupias, 2005).

Merujuk pada pendapat Koentjaraningrat (Koentjaraningrat,1994:9), hubungan spiritulitas masyarakat adat Kampung Pulo dengan alam menggambarkan ekspresi dari orientasi nilai budaya mereka terhadap hakikat hidup, hakikat alam, dan hakikat hubungan antar sesama manusia. Sedangkan orientasi nilai budaya mereka terhadap hakikat alam adalah bahwa mereka berusaha untuk selaras dengan alam. Orientasi ini melahirkan sikap dan tingkah laku yang berupaya untuk tidak menentang kekuatan alam. Sedangkan orientasi nilai budaya terhadap hakikat hubungan antar sesama manusia terungkap adanya orientasi vertikal dari masyarakat adat Kampung Pulo dengan menempatkan kuncen sebagai satusatunya pemimpin yang memiliki kewenangan memimpin upacara-upacara khusus (adat) tersebut.

Upacara-upacara adat sebagaimana terungkap pada deskripsi hasil penelitian, terlepas dari benar atau tidaknya menurut kajian fiqh Islam, ternyata memiliki hubungan dengan agama Islam, yaitu adanya prosesi ziarah ke makam Embah Dalem Arif Muhammad, yaitu makam yang dikeramatkan oleh masyarakat setempat, dan adanya shalat sunat yang dilaksanakan sebelum kegiatan inti memandikan benda-benda pusaka.

Masyarakat adat Kampung Pulo dalam kehidupannya dibimbing oleh nilai-nilai budaya (adat istiadat, tradisi, pantangan/larangan) yang mereka peroleh secara turun temurun dari karuhun mereka. Menurut kepercayaan mereka, dengan menjalankan adat itu, berarti mereka menghormati para karuhun. Oleh karena itu, segala sesuatu yang datangnya bukan dari ajaran karuhun dan tidak dilakukan karuhunnya dianggap sebagai sesuatu yang tabu untuk dikerjakan, dan apabila hal-hal tersebut dilakukan maka berarti mereka melanggar adat, tidak menghormati karuhun, dan akan menimbulkan malapetaka.

Nilai-nilai budaya yang membimbing masyarakat adat itu merupakan/cerminan masyarakat adat Kampung Pulo yang menurut pandangan (Bushar Muhammad 2002:42), lahir dari suatu kebutuhan hidup yang nyata, cara hidup, dan pandangan hidup yang keseluruhannya merupakan kebudayaan masyarakat adat Kampung Pulo itu. Dalam pandangan Saini KM (Saini, 2005), nilainilai budaya masyarakat adat itu tersebar dalam berbagai bidang yang sangat luas, dari sikap hidup, gagasan-gagasan, perilaku dan upacara-upacara sampai kepada benda-benda dan perlengkapan yang dipergunakan masyarakat itu sejak keberadaannya. Dengan demikian, maka nilai-nilai budaya yang terdapat pada masyarakat adat Kampung Pulo adalah khas, sesuai dengan jiwa masyarakat adat Kampung Pulo.

Masyarakat adat Kampung Pulo memaknai nilai-nilai budaya sebagai seperangkat ketentuanketentuan adat yang harus mereka jalankan sebagai pedoman tingkah laku sehari-hari mereka dan yang mereka peroleh dari karuhun mereka secara turun temurun.

Nilai-nilai budaya masyarakat adat Kampung Pulo mewujud dalam bentuk ide-ide atau gagasan, dalam bentuk aktivitas atau tingkah laku berpola, dan dalam bentuk budaya fisik. Dalam wujud ideide atau gagasan, pada masyarakat adat nilai-nilai Kampung Pulo terdapat paribasa (peribahasa) yang mengandung budaya yang dapat diinternalisasikan dalam pendidikan karakter sebagaimana dapat dijelaskan berikut:

1. Balungbung timur, caang bulan opal belas jalan gede sasapuan, yang mengandung nilai budaya bahwa adalah perbuatan terpuji untuk berbuat baik sangka serta penuh keikhlasan saling memaafkan dan tidak menaruh dendam.

2. Silih asah, silih asih jeung silih asuh, yang secara luas berarti silih asih ku pangarti, silih asah ku pangabisa, silih asuh ku pangaweruh. Silih asih adalah makna transformasi kasih sayang sejati antara satu sama lainuntuk menghindari dampak yang dapat mengganggu. Silih asah adalah makna perlunya kebersamaan sebab dalam menghadapi tantangan dan kesempatan tiada orang yang sendirian bila terlibat dalam suatu lingkungan dibutuhkan 
kerjasama dengan orang lain, untuk itu perlu iklim kondusif dari pimpinan yang arif, bijaksana dan bekerja secara sistematis

3. Cageur, bageur, bener, pinter, wanter, yang mengandung nilai budaya bahwa kita harus selalu sehat, baik budi pekerti, benar, pintar dan berani.

4. Abong biwir teu diwengku, abong letah teu tulangan, yang mengandung nilaibudaya bahwa apa yang akan dikatakan sebelumnya harus dipikirkan matang-matang.

5. Beuntik curuk balas nunjuk, capetang balas miwarang, yang mengandung nilai budaya bahwa orang yang hanya bisa memerintah tanpa dapat melaksanakannya, nilainya rendah di mata masyarakat. Nilai budaya yang terkandung dalam paribasa ini adalah bahwa nilai yang terbaik adalah nilai keteladanan.

6. Cikaracak ninggang batu, faun-faun jadi legok, yang mengandung nilai budaya untuk ulet, tekun, dan rajin dalam menuntut ilmu.

7. Ciri sabumi, cara sadesa, yang mengandung nilai budaya bahwa adalah perbuatan terpuji untuk menghargai peraturan-peraturan, kebiasaan-kebiasaan dan bahasa-bahasa yang berlaku di setiap daerah.

8. Kudu caringcing pageuh kancing, saringset pageuh iket, yang mengandung nilai budaya bahwa kita hams selalu siap dan waspada dalam mengarungi kehidupan.

9. Cul dogdog tinggal igel, yang mengandung nilai budaya bahwa sangat tercela orang yang selalu mengerjakan sesuatu dengan serakah dan lupa diri.

10. Dijieun hulu teu nyanggut, dijieun buntut teu ngepot, yang mengandung nilai budaya bahwa sangat tercela orang yang keras kepala tidak mau dibimbing sehingga pekerjaannya terbengkalai.

11. Hade ku omong, goreng ku omong, yang mengandung nilai budaya bahwa sangat terpuji bagi orang yang mampu menjaga lidahnya.

12. Herang caina, beunang laukna, yang mengandung nilai budaya bahwa sangat terpuji orang yang memiliki sifat bijaksana dan adil dalam mencapai maksud atau dalam menyelesaikan masalah.

13. Kudu leuleus jeujeur, liat tali, yang mengandung nilai budaya bahwa kita harus bijaksana, sabar, dan lemah lembut dalam menghadapi setiap peristiwa hidupnya.

14.Kudu ngaindung ka waktu, ngabapa ka zaman, yang mengandung nilaibudaya agar dapat menyesuaikan tingkah lakunya sesuai perubahan dengan tetap berpatokan padajati dirinya.
Dalam bentuk fisik, nilai-nilai budaya pada masyarakat adat Kampung Pulo diwujudkan dalam penataan kompleks bangunan rumah dan bentuk rumah panggung dengan pola dan arsitektur yang khas. Cara penataan bangunan rumah di Kampung Pulo adalah melingkar membentuk huruf $\mathrm{U}$ atau disebut ngariung (berkumpul, menyatu). Semua bangunan rumah yang ada di Kampung Pulo termasuk jenis bangunan panggung, dimana seluruh bangunan tersebut berdiri di atas bambu penyangga yang disebut tatapakan (tempat bertumpu atau penyangga) yang diletakkan pada setiap pojok serta bagian konstruksi yang menahan beban yang eukup besar.

Bagian lantai rumah dibuat dari palupuh, yakni lembaran bambu hasil eereahan atau tumbukan yang menyatu saling mengikat. Hasil eereahan tersebut membentuk celah-celah memanjang tidak beraturan yang berfungsi sebagai ventilasi udara dan bawah serta dapat digunakan untuk membuang debu dari atas lantai. Sedangkan bagian dindingnya terbuat dari anyaman bambu yang disebut bilik, berfungsi sebagai penutup bangunan maupun penyekat ruangan. Bilik tersebut memiliki lubang-lubang kecil seperti pori-pori yang juga berfungsi sebagai ventilasi untuk menyalurkan udara dari Iuar ruangan maupun eahaya dari luar ruangan atau sebaiknya. Dengan demikian suhu dalam ruangan selalu terjaga secara alami sesuai dengan kondisi euaca alam di luar. Selain itu untuk keperluan eahaya tidak perlu mengandalkan cahaya yang masuk sepenuhnya melalui jendela.

Lima buah bangunan rumah di Kampung Pulo menggunakan bentuk bubungan (suhunan) panjang atau disebut juga suhunan jolopong (membujur, tergolek lurus) dengan atap dari genting. Sedangkan satu lagi menggunakan bentuk suhunan julang ngapak (manuk Julang dalam bahasa Sunda sedang mengepakkan sayap) dengan bahan ijuk. Bangunan yang disebutkan terakhir ini merupakan prototipe dari bangunan tradisional Sunda asli hasil renovasi oleh pihak pemerintah dan selanjutnya ditetapkan sebagai eagar budaya.

Bentuk suhunan julang ngapak memiliki empat bidang, dua diantaranya disusun seperti halnya suhunan Jolopong. suhunan julang ngapak terdapat atap tambahan dari bambu di kedua sisinya, yaitu di depan dan di belakang dengan kemiringan yang lebih landai yang disebut leang-leang. Pada suhunan julang ngapak atapnya menggunkan anyaman ijuk. Di kedua ujung atasnya diikat dengan teknik capit hurang (jepitan udang).

Pada bangunan prototipe suhunan julang ngapak daun pintunya juga menggunakan 
anyaman bambu yang disebut sarigsig (anyaman) sedangkan bangunan lainnya sudah menggunakan daun pintu dari kayu. Keistimewaan dari teknik sarigsig tersebut adalah bisa melihat dari dalam ke luar tetapi yang dan luar tidak dapat melihat ke dalam. Udara segar dari luar pun masih dapat mengalir melalui celah-celah sarigsig tersebut. Pada bagian muka pintu rumah terdapat tangga yang disebut golodog yang terbuat dari bambu atau kayu.

Mereka tetap mengamalkan beberapa paribasa (peribahasa) yang merupakan wujud ide atau gagasan dalam nilai-nilai budaya mereka dan mereka juga mempertahankan berbagai ketentuanketentuan adat, yaitu a) tidak berziarah ke makam Embah Dalem Arif Muhammad pada hari Rabu; b) tidak menambah jumlah bangunan rumah; c) tidak merubah bentuk atap rumah selain dalam bentuk memanjang (suhunan Jolopong dalam bahasa Sunda); d) tidak memukul gong besar; e) tidak memelihara temak besar berkaki empat; dan f) mewariskan rumah- rumah adat mereka kepada anak perempuan. Disamping itu, mereka juga tetap menata komplek bangunan rumah dalam posisi ngariung (berkumpul) berbentuk huruf $\mathrm{U}$, dan mendirikan bangunan rumah panggung dengan pola dan arsitektur yang khas. Sungguhpun mereka sudah tidak lagi mengetahui secara pasti mengapa nilai-nilai budaya itu tetap dipertahankan, tetapi mereka tetap melaksanakannya. Mereka hanya tahu bahwa semua itu adalah sudah adatnya, dan oleh karenanya mereka akan menjalankan apa yang selama ini telah dilakukan oleh orang-orang tua mereka.

\section{Pembelajaran Nilai-nilai Kementerian Energi dan Sumber Daya Mineral}

Nilai-nilai KESDM tersurat dalam Peraturan Menteri ESDM nomor 1808 K/07/MEM/2015 meliputi Jujur, Profesional, Melayani, inovatif dan berarti. Muatan materi ini diberikan pada pelatihan yang dilaksakan PPSDM Aparatur, hal ini sebagai bentuk internalisasi nilai organisasi. Metoda pembelajaran materi nilai-nilai Kementerian ESDM, dilakukan dengan berbagai macam cara, mulai diskusi, brainstorming, studi kasus, film pendek dan lain sebagainya.

Dari pengalaman pelaksanaan pembelajaran ini studi kasus dapat menjadi andalan menanamkan peran nilai dalam membentuk budaya organisasi.

Nilai kampung Pulo dapat menjadi sumber materi dalam studi kasus internalisasi nilai yang mengakar sehingga anggotanya komitmen terhadap budaya tersebut.

\section{KESIMPULAN}

Dalam pembelajaran nilai organisasi dapat menggunakan nilai yang berkembang di lingkungan masyarakat sescara kohesif mampu merefleksikan karakter yang kuat dalam memegang teguh budaya. Hal ini membantu siswa mencerna komitmen kuat anggota organisasi dalam menunjukkan nilai sehingga menjadi budaya yang organik menuju pencapaian visi dan misi organisasi.

\section{Daftar Pustaka}

Aziz, W. (2007). Pendidikan Pancasila dan Kewarganegaraan (PPKN). Jakarta: Penerbit Universitas Terbuka.

Bertens, K. (2007). Etika. Jakarta: Gramedia.

Darwis, Ranidar. (1998). Mengenal Hukum Adat Indonesia. Bandung: FPIPS IKIP Bandung.

Harsojo. (1970). "Kebudayaan Sunda", dalam Koentjaraningrat. (1970). Manusia dan Kebudayaan Di Indonesia. Jakarta: Penerbit Djambatan.

Ihsan, F. (1997). Dasar-Dasar Kependidikan. Jakarta: Rineka Cipta.

Koentjaraningrat. (1994). Metode-metode Penelitian Masyarakat. Jakarta: PT Gramedia Pustaka Utama.

Loupias, Henry H. (2005). "Kampung Pulo Wujud Arsiterktur Tradisional Sunda", Pikiran Rakyat (15 Januari 2005).

Moeheriono. 2012. "Pengukuran Kinerja Berbasis Kompetensi”. Jakarta: Raja. Grafindo Persada. Pramono, (Agustus 2012)

Muhaimin. (2004). Paradigma Pendidikan islam Upaya Mengefektifkan Pendidikan Islam di Sekolah. Bandung: PT Remaja Rosdakarya.

Muhammad, Bushar. (2002). Asas-asas Hukum Adat: Suatu Pengantar. Jakarta: PT Pradnya Paramita.

Munawar, Zaki. (2002). Cagar Budaya Candi Cangkuang \& Sekitarnya. Tidak diterbitkan.

Raharjo. (2010). Pendidikan Karakter sebagai Upaya Menciptakan akhlak Mulia, Jurnal Pendidikan dan Kebudayaan (Vol. 16). Jakarta: Balitbang kementrian Pendidikan Nasional.

Saini KM. (2005). "Kearifan Lokal Di Arus Global". Pikiran Rakyat (30 Juli dan 6 Agustus 2005).

Sugiyono. (2011). Metode Penelitian Pendidikan Pendekatan Kuantitatif, Kualitatif, dan R\&D. Bandung: Alfabeta. 